\title{
Neurological Disorders in Khammam District with Special Reference to Brain Stroke
}

\author{
Authors \\ Jagadeesh Babu. $K^{1}$, Ravi Chandra. $K^{2}$ \\ ${ }^{1}$ Associate Professor, Department of Neurosurgery, Mamata Medical College, Khammam, Telangana \\ ${ }^{2}$ Assistant Professor, Department of Neurosurgery, Mamata Medical College, Khammam, Telangana State \\ Corresponding Author \\ Jagadeesh Babu. K
}

Associate Professor, Department of Neurosurgery, Mamata Medical College, Khammam, Telangana Phone no: 8374590275, Email: jagadeeshneurok@gmail.com

\begin{abstract}
Neurological disorders had special significance in developing countries. The study was conducted at the Mamata medical college and General hospital, Khammam, Telangana state for 3 years. The percentage of commonly occurring neurological disorders are epilepsy (36\%), headache (17\%), stroke(16\%) and peripheral nerve disorders $(13.2 \%)$. Ischemic stroke is seen $66 \%$ of followed by haemorrhagic stroke. Stoke is mainly due to hypertension, cardiac diseases and meningitis. In our study hypertension is the common risk factor followed by alcohol consumption and smoking. About 30\% patients had smoking and alcohol consumption habits along with hypertension. Diabetes, heart disease and diabetes are also contributing for stroke in Indian people.
\end{abstract}

Keywords-Neurological disorders, stroke, risk factors, India, cerebro vascular disorders.

\section{INTRODUCTION}

Developing countries, including India are passing through a phase of epidemiological transition with increasing burden of non-communicable diseases (NCD) consequent to transformation of scenario with improvement of health care services in preventive and promotive domains. Among the NCDs, neurological disorders form a significant proportion of global burden of diseases ${ }^{[1,2]}$. A wide spectrum of neurological disorders were detected, including common disorders such as epilepsy, febrile convulsions, headache, cerebro-vascular disorders, stroke, tremors and mental retardation and other with lower prevalence comprising of Parkinson's disease and peripheral neuropathy ${ }^{[3,4]}$.
The prevalence of neurological disorders was found to be $967-4070$ with an average of 2394 per lakh population ${ }^{[5]}$.

Stroke is defined as focal neurological deficit resulting from diseases of cerebral vasculature and its contents. ${ }^{[6]} \mathrm{A}$ stroke is caused by the interruption of the blood supply to the brain, usually because a blood vessel bursts or is blocked by a clot. This cuts off the supply of oxygen and nutrients to the brain, causing damage to the brain tissue. The WHO clinically defines stroke as 'the rapid development of clinical signs and symptoms of a focal neurological disturbance lasting more than 24 hours or leading to death with no apparent cause other than vascular origin, ${ }^{[7]}$. Ischaemic strokes are 
caused by sudden occlusion of arteries supplying the brain, either due to a thrombus at the site of occlusion or formed in another part of the circulation. It account for $50 \%-85 \%$ of all strokes worldwide ${ }^{[8]}$. Haemorrhagic strokes are caused by subarachnoid haemorrhage - bleeding from one of the brain's arteries into the brain tissue or intracerebral haemorrhage - arterial bleeding in the space between meninges. This category of stroke account for $1 \%-7 \%$ and $7 \%-27 \%$ respectively of all strokes worldwide ${ }^{[8]}$. The most common symptom of a stroke is sudden weakness or numbness of the face, arm, or leg, most often on one side of the body, occurring in $90 \%$ of the strokes .Other symptoms include confusion; difficulty speaking or understanding speech; difficulty seeing with one or both eyes; difficulty walking, dizziness, and loss of balance or coordination; severe headache with no known cause; fainting or unconsciousness. The effects of a stroke depend on which part of the brain is injured and how severely it is affected. Avery severe stroke can cause sudden death. It leaves the patients with residual disabilities like physical dependence, cognitive decline, depression, and seizures.

Globally, stroke is the third commonest cause of mortality ${ }^{[9]}$ and the fourth leading cause of disease burden ${ }^{[10]}$. Epidemiology of stroke is unique in nature. The factors attributed are hypertension, diabetes mellitus, obesity, smoking, urbanization, stress and many unidentified social and cultural factors. The prevalence of disability among stroke survivors is between $24-54 \%{ }^{[11]}$. The progressive decrease in stroke mortality observed in the last few decades, and the subsequent increase of survivors with residual impairments and disabilities, have been accompanied by a growing interest in the factors that could interfere with functional outcome and quality of life ${ }^{[12]}$. Depression is considered as the strongest predictor of poor quality of life among stroke survivors ${ }^{[13]}$.

The aim of this study is to summarise the neurological disorders with special reference to stroke and the knowing about the different risk factors contributing to stroke.

\section{MATERIALS AND METHODS}

The study was conducted at the Mamata medical college and General hospital, Khammam, Telangana state during the period January 2014-December2016 for 3 years after taking permission from hospital ethics committee. The patients visiting neurology ward willing to participate in this study were included after taking written consent form. All the patients were grouped according to their problems and history of risk factors were recorded. All the values were expressed in percentages.

\section{RESULTS}

A total of 1326 patients were included in this study. All were aged between 35 - 75 years and 672 of them were males and 654 were females. Mean body weight of patients was $68.25 \mathrm{Kgs}$. The neurological disorders in patients were shown in table.1.

Table 1: Different types of neurological disorders

\begin{tabular}{|l|c|c|}
\hline Nerological disorder & $\begin{array}{c}\text { No of } \\
\text { patients }\end{array}$ & \% patients \\
\hline Epilepsy & 482 & 36.3 \\
\hline Febrile convulsions & 74 & 5.5 \\
\hline Headache & 228 & 17.1 \\
\hline Stroke & 221 & 16.6 \\
\hline Mental retardation & 10 & 0.75 \\
\hline Parkinson's disease & 21 & 1.6 \\
\hline Tremors nerve & 65 & 4.9 \\
\hline Poliomyelitis & 20 & 1.5 \\
\hline $\begin{array}{l}\text { Peripheral } \\
\text { disorders }\end{array}$ & 23 & 13.2 \\
\hline $\begin{array}{l}\text { Postencephalitic } \\
\text { sequelae }\end{array}$ & 1.7 \\
\hline
\end{tabular}

In this study Epilepsy is commonly seen neurological disorder followed by head ache and stroke. Store is one of important neurological disorder leading to death or physical impairment. In this study stoke is divided into 3 subgroups shown in table 2, different etiological factors were shown in table 3and different risk factors were shown in table 4.

Table 2: Different types of stroke

\begin{tabular}{|l|c|c|}
\hline Type of stroke & No of patients & \% patients \\
\hline Ischemic stroke & 147 & 66.5 \\
\hline Haemarrhagic stroke & 60 & 27.1 \\
\hline Venous stroke & 14 & \\
\hline
\end{tabular}


Table 3: Etiological factors of stroke

\begin{tabular}{|l|c|c|}
\hline Cause of stroke & $\begin{array}{c}\text { No of } \\
\text { patients }\end{array}$ & $\begin{array}{c}\% \\
\text { patients }\end{array}$ \\
\hline Cerebral venous thrombosis & 14 & \\
\hline Rheumatic heart disease & 22 & \\
\hline Tuberculosis meningitis & 25 & \\
\hline bacterial meningitis & 28 & \\
\hline Cardioembolism & 28 & \\
\hline Cardiomyopathies & 20 & \\
\hline Tumours & 4 & \\
\hline Hypertension & 57 & \\
\hline $\begin{array}{l}\text { Pregnancy-induced } \\
\text { hypertension } \\
\text { and puerperal sepsis }\end{array}$ & 2 & \\
\hline Others & 21 & \\
\hline
\end{tabular}

Table 4: Factors influencing stroke

\begin{tabular}{|l|c|}
\hline Factors effecting stroke & $\%$ patients \\
\hline Alcohol consumption & 33 \\
\hline Diabetes & 8 \\
\hline Family history of stroke & 4 \\
\hline Heart disease & 20 \\
\hline High cholesterol & 14 \\
\hline Hypertension & 38 \\
\hline Obesity & 15 \\
\hline Smoking & 30 \\
\hline
\end{tabular}

Out of 221 stroke patients 48 members were died during the period of 3 years, 128 survived with residual impairments and disabilities, and most of survivors were in severe depression.

\section{DISCUSSION}

In this study epilepsy is the most common neurological disorder followed by head ache and stroke. The crude prevalence rate of neurological disorders in India varied from 967-4,070 per 100000 populations with an average of 2394 per 100000 populations ${ }^{[14]}$. The neurological disorders were more common in rural compared to the urban population with a ratio of 1.9:1 and the prevalence rate was higher in females than males in Bangalore and Malda ${ }^{[15,16]}$. It is noteworthy that epilepsy, headache, febrile convulsions and cerebrovascular, disorder together constituted $80 \%$ of all neurological disorders in the community, and others with lower prevalence comprising of Parkinson's disease and peripheral neuropathy.

In our study epilepsy incidence is about $30 \%$ in neurological disorders. The global burden of disease study of 2000 provides an estimate of 50 million people with epilepsy and more than $80 \%$ of them in developing countries ${ }^{[17]}$. The mean crude prevalence rate was 5.7 per 1000 population. Essential tremors were the commonest among all movement disorders with overall prevalence rates varying over a wide range of 8-395/100000 ${ }^{[14]}$.

Stroke is a major public health problem. Stroke is the second leading cause of death and one of the leading causes of disability. Estimated prevalence rates of stroke for the years 2000 and 2015 are 108 and 133 per 100,00 population, respectively ${ }^{[18]}$. Age has been shown to have a strong association with the incidence of stroke. While the peak age of stroke occurrence is 55-65 years ${ }^{[19]}$. Ischemic stroke is the most common subtype of stroke followed by intra cerebral haemorrhage and accounts for approximately 50\% and $20 \%$ respectively. Cerebral venous thrombosis and rheumatic heart disease are the leading causes of stroke in the young in India ${ }^{[20]}$.

A recent study from Pakistan ${ }^{[21]}$ in 50 young stroke patients also found infective meningitis including tuberculosis meningitis and bacterial meningitis as the leading cause of stroke $(34 \%)$. The second most commoncause was cardioembolism (20\%) comprising Valvular heart diseases (14\%), Cardiomyopathies (4\%), and atrial myxoma (2\%). Hypertension was found in $14 \%$ cases. Pregnancy related causes were $12 \%$. Systemic lupus erythematous and nephritic syndrome was $4 \%$ each. Various causes which constitute $4 \%$ or less were grouped together as miscellaneous and they include hyperhomocysteinaemia and hyperlipidaemias. Washington ${ }^{[22]}$ study found cardiac embolism (31.1\%), hematologic and other (19.8\%) small vessel (lacunar) disease (19.8\%), nonatherosclerotic vasculopathy $(11.3 \%)$, illicit drug use $(9.4 \%)$, oral contraceptive use $(5.2 \%)$, large artery atherosclerotic disease $(3.8 \%)$, and migraine (1.4\%) in their 428 young ischemic stroke patients.

A study from Rome ${ }^{[23]}$ confirmed smoking in $56 \%$ of patients, hypertension in $23 \%$, dyslipidemia in $15 \%$, migraine in $26 \%$, and diabetes mellitus in $2 \%$ in 394 young ischemic stroke patients. Our results were in comparision with the above studies. 
In our study hypertension is the common risk factor followed by alcohol consumption and smoking. About 30\% patients has hypertension with smoking and alcohol consumption habits. Diabetes, heart disease and obesity are also the contributing factors for stoke. Cerebrovascular disorders (CVD) are increasing in prevalence and incidence in India due to rapid escalation of risk factors including hypertension diabetes mellitus, smoking and obesity affecting considerable proportion of adult population. $20-30 \%$ of strokes occur in people younger than 45 years and is more frequently seen in India compared to the west ${ }^{[24]}$ In arecent study conducted in Gujarat, It was found that modifiable risk factors such as hypertension (40\%), alcoholism (35\%), smoking (28\%) and hyperlipidemia (17\%) are the commonest cause of stroke among the elderly ${ }^{[25]}$; and smoking, alcoholism, increased BMI, diabetes and hypertension are significantly associated with strokes among young people ${ }^{[26]}$. Hyperlipidemia and diabetes are known to be the risk factor for large artery atherosclerotic and small vessel occlusive disease ${ }^{[27]}$.

In conclusion, neurological disorders effecting significant proportion of population. Stroke is most common problem either leading to death or if survived with residual impairments and disability. In India there is need for establishment of neurological heath care centers which will helps the rural Indian for immediate treatment facilities for stoke like neurological disorders.

\section{ACKNOWLEDGEMENT}

The authors were thankful to the Mamata medical college and Authors acknowledge the immense help received from the scholars whose articles are cited and included in references of this manuscript.

\section{REFERENCES}

1. Murray CJ, Lopez AD. The global burden of disease. Boston: Harvard School of Public Health; 1996.

2. National commission on macroeconomics and health. Burden of diseasein India. Ministry of Health and Family Welfare,
Government of India,New Delhi; 2005. p. 367.

3. Das SK, Biswas A, Roy T, Banerjee TK, Mukherjee CS, Raut DK, et al.A random sample survey for prevalence of major neurological disordersin Kolkata. Indian J Med Res 2006;124:163-72.

4. Das SK, Biswas A, Roy J, Bose P, Roy T, Banerjee TK, et al. Prevalenceof major neurological disorders among geriatric population in themetropolitan city of Kolkata. J Assoc Physicians India 2008;56:175-81.

5. Gourie-Devi M. Epidemiology of neurological disorders in India:Review of background, prevalence and incidence of epilepsy, stroke,Parkinson's disease and tremors. Neurol India 2014;62:588-98.

6. Munjal YP, API Textbook of Medicine 9th Edition 2012. Jaypee Brothers Medical Publishers(P) Ltd. p. 1401-10.

7. World Health Organisation. Preventing Chronic Diseases: A vital investment. Geneva, Switzerland. 2005.

8. Feigin V, Lawes C, Bennet D, Barker Cello S, Parag V. Worldwide stroke incidence and early case fatality in 56 population based studies: a systematic review. Lancet Neurology 2009; 8 (4): 355- 369

9. C.Warlow, C. Sudlow, M. Dennis, J.Wardlaw, and P. Sandercock, "Stroke," Lancet, vol. 362, no. 9391, pp. 1211-1224, 2003.

10. K. Strong, C. Mathers, and R. Bonita, "Preventing stroke:saving lives around the world," Lancet Neurology, vol. 6, no.2, pp. 182-187, 2007.

11. Sacco RL. Risk factors, outcomes, and stroke subtypes for ischemic stroke. Neurology 1997;49:39-44.

12. Sarti C, Rastenyte D, Cepaitis Z, Tuomilehto J. International trends in mortality from stroke, 1968 to 1994. Stroke 2000;31:1588601 
13. Kim P, Warren S, Madill H, Hadley M. Quality of life of stroke survivors. Qual Life Res 1999;8:293-301

14. Gourie-Devi: Epidemiology of Neurological disorders in India, Neurology India | NovDec 2014 | Vol 62 | Issue 6

15. Gourie-Devi M, Gururaj G, Satishchandra P, Subbakrishna DK. Prevalence of neurological disorders in Bangalore, India:A community-based study with a comparison between urban and ruralareas. Neuroepidemiology 2004;23:261-8

16. Das SK, Sanyal K. Neuroepidemiology of major neurological disorders in rural Bengal. Neurol India 1996;44:47-58.

17. Leonardi MT, Ustun TB. The global burden of epilepsy. Epilepsia 2002;43:21-5

18. Shah B, Kumar N, Khurana S. Assessment of burden of non-communicablediseases. Indian Council of Medical Research; 2006. p. 154

19. P. M. Dalal, "Burden of stroke - Indian perspective," Journal of Association of Physicians of India, vol. 52, pp. 695-696, 2004.

20. K. Srinivasan, "Ischemic cerebrovascular disease in the young. Two common causes in India," Stroke, vol. 15, no. 4, pp. 733735, 1984

21. S. Samiullah, M. Humaira, G. Hanif, A. A. Ghouri, andK. Shaikh, "Etiological patterns of stroke in young patientsat a tertiary care hospital," Journal of the Pakistan MedicalAssociation, vol. 60, no. 3, pp. 201204, 2010.

22. S. J. Kittner, B. J. Stern, M. Wozniak et al., "Cerebral infarction in young adults: the Baltimore-Washington CooperativeYoung Stroke Study," Neurology, vol. 50, no. 4, pp. 890-894,1998.

23. M. Rasura, A. Spalloni,M. Ferrari et al., "A case series of youngstroke in Rome," European Journal of Neurology, vol. 13, no. 2, pp. 146-152, 2006.
24. Dalal PM. Burden of stroke: Indian perspective. Int J Stroke2006;1:164-6

25. R P Eapen, J.H Parikh, N.T Patel. A Study of Clinical Profile and Risk Factors of Cerebrovascular Stroke.Gujarat medical journal 2009. Vol 64. No: 2.pp:221-228.

26. Prasad Kameshwar, Singhal Kapil K Stroke in young: An Indian perspective. Year: 2010 Volume: 58.Issue Number: 3. Page: 343-350

27. Furie KL, Kasner SE, Adams RJ, et al. Guidelines for the prevention of stroke in patients with stroke or transient ischemic attack: a guideline for healthcare professionals from the American heartassociation/ American stroke association. Stroke 2011; 42:227e 76 